\title{
Treatment Response in Behaviour Disorders in Rett Syndrome
}

\author{
Ana Roche Martínez ${ }^{1}$, Marc Turon², Laura Callejón-Póo ${ }^{2}$, Elisenda Sole ${ }^{3}$, \\ Judith Armstrong ${ }^{4}$, Mercé Pineda ${ }^{1}$ \\ ${ }^{1}$ Child Neurology Department, Sant Joan de Déu Children's Hospital, Barcelona, Spain \\ ${ }^{2}$ Child Neuropsychology Department, Sant Joan de Déu Children's Hospital, Barcelona, Spain \\ ${ }^{3}$ Child Cardiology Department, Sant Joan de Déu Children's Hospital, Barcelona, Spain \\ ${ }^{4}$ Molecular Genetics Laboratory, Sant Joan de Déu Children's Hospital, Barcelona, Spain \\ Email: aroche@hsjdbcn.org
}

Received February 17, 2013; revised April 2, 2013; accepted May 3, 2013

Copyright (C) 2013 Ana Roche Martínez et al. This is an open access article distributed under the Creative Commons Attribution License, which permits unrestricted use, distribution, and reproduction in any medium, provided the original work is properly cited.

\begin{abstract}
RTT girls suffer periods of abnormal behavior from early infancy, including irritability and sleep disorders or anxiety in the first years of life, and a more depressed mood after adolescence, all of which influences their quality of life. An association between emotional and behavioral disorders and various neurochemical changes in the synapses of cortical and subcortical brain regions has been established; also, cortisol levels in the blood vary during stress. The main purpose of this study was to improve mood and behavior disorders in RTT patients with venlafaxine (SNRI), and compare the results with citalopram (SSRIs) during 6 - 8 weeks, to determine which drug offered greater efficacy and fewer side effects, as well as to compare them to risperidone, and to correlate cortisol levels in saliva with stress and drug response. Eleven patients, aged 5 to 26 years old, agreed to participate in this study; neuropsychological tests (Mullen and Vineland scales), quality of life and quality of sleep scales, blood tests, EKG and EEG were performed before and after treatment. Only 2 patients completed the three months trial. Improvement in mood and behavior was not statistically significant for patients; differences in neurodevelopment and quality of life or sleep scales were not significant either; no serious adverse effects were observed. Cortisol levels in saliva decreased in $50 \%$ of the patients after the first month of treatment, although this was not statistically significant.
\end{abstract}

Keywords: Cortisol, Mood and Behavior, Rett Syndrome; SSRI; SNRI

\section{Introduction}

Rett syndrome (RTT) is a neurodevelopment disease which affects $1 / 10,000$ newborn girls. The diagnosis is based on a series con clinical criteria (Table 1). The classical form consists of apparently normal development during the first 6 to 12 months of life (Phase 1), followed by global deterioration (Phase 2), with loss of acquired language and purposeful use of hands, onset of hand stereotypes and loss of social interest; clinical stability or even improvement occurs around 4 to 5 years of age (Phase 3 ) but sometimes further deterioration after adolescence may take place (Phase 4); atypical forms are either clinically milder or more severe than the classical form.

RTT girls suffer periods of abnormal behaviour: during Phase 2 [1,2], between 18 months and 3 years of age, irritability, sleep disorders, crying tantrums and loss of social interest appear; during Phase 3, half of these pa- tients develop behavioural disorders: younger girls (5 to 10 years) tend to scream, hit, show anxiety, and exhibit inattention and hyperactive behaviours, and sometimes self-mutilation. Among preadolescents and adolescents (10 - 20 years) melancholy, insomnia, loss of appetite, loss of social interest, unexplained screams and signs of depression are more frequent. Anxiety, stress and fear are also commonly seen in young women with RTT. These behaviours interfere not only with the patient's quality of life, but also with therapeutic and educational intervenetions, as well as with their families' day-to-day life. Behavioural changes with age and their management become a challenge for caregivers and physicians.

An association between emotional and behavioural disorders and neuro-biochemical changes in the synapses of cortical and subcortical brain regions has been established. Synaptic function abnormalities contribute to several neuropsychiatric diseases $[3,4]$. Several authors sug- 
gest that dysfunction in brain neurotransmitters in RTT patients involves glutamate [5-7], GABA [8], norepinephrine [9], serotonin [10] and dopamine [11]. These defects have also been demonstrated in the mouse model for RTT [12]. The primary behaviour alterations in patients with RTT are most likely the result of changes in the monoaminergic systems: treating disruptive behaviours with selective serotonin reuptake inhibitors (SSRI) [13-18] and serotonin and noradrenaline reuptake inhibitors or SNRI [19-23] can improve behaviour.

Published data suggest high levels of corticotropine releasing factor (CRF) in mouse models [24] and cortisol blood levels during stress and anxiety [25-27].

Measurement of cortisol in oral saliva reveals a wellknown correlation with levels in blood: saliva cortisol levels may be useful as a laboratory parameter of stress, and as a reflection of changes occurring in Neurometabolic Rett syndrome [28-30].

Table 1. Diagnostic criteria for RTT.

\begin{tabular}{l}
\hline Diagnostic criteria for the classical form \\
\hline 4 main criteria \\
Diagnostic criteria for the atypical variants of RTT \\
\hline 2 main criteria \\
5 support criteria \\
Main criteria \\
Partial or total loss of hand skills \\
Partial or total loss of verbal language \\
Inability for walking or apraxic gate \\
Hand stereotypies (winging, washing, twisting, hand-to mouth, \\
clapping...) \\
Support criteria \\
Breathing disturbances while awake \\
Bruxism while awake \\
Sleep pattern disturbance \\
Abnormal muscle tone \\
Abnormal peripheral circulation: cold hands and feet \\
Scoliosis/kyphosis \\
durowing the follow up \\
\hline
\end{tabular}

The main purpose of this study was to improve mood and behaviour disorders in RTT patients with venlafaxine, a reuptake inhibitor of serotonin and norepinephrine (SNRI), and compare the results with citalopram, a selective inhibitor of reuptake inhibitors (SSRIs), in order to determine which drug showed greater efficacy and fewer undesirable side effects. Other purposes of the study were to determine whether the level of salivary cortisol was related to the intensity of mood disorder and drug response; to determine whether the effects of the two drugs were related to age; to determine whether these effects were related to the genotype; to describe what type of altered behaviour was further modified after therapeutic intervention; and to evaluate the putative improvement in the patients' and their families' quality of life after treatment.

The study aimed to confirm the initial hypothesis according to which some improvement would be achieved after treating the behavioural problems of RTT girls with a serotonin reuptake inhibitor.

\section{Material and Methods}

Treatment with serotonin reuptake inhibitors was proposed to 15 Spanish RTT patients of Caucasian origin, aged 5 to 26 years of age; they were all controlled at the same hospital and all of them fulfilled the clinical criteria for the classical form of RTT. All patients were clinically evaluated before being included in the study to rule out other medical problems that might cause alterations in mood or behaviour, such as severe reflux or esophagitis, fractures, gallbladder problems, severe constipation, spasms, severe dystonia, uncontrolled seizures, dental problems or other medical problems.

Informed consent was obtained from the families in accordance with the hospital ethics committee.

\subsection{Inclusion and Exclusion Criteria}

- Inclusion criteria were:

- major disruptive behaviours that did not respond to previous treatments

- absence of medical problems recognized as responsible for the abnormal behaviour

- Exclusion criteria were:

- uncontrolled epilepsy (seizures in the previous 6 months)

- serious medical problems, causing pain and discomfort

- QT corrected segment (QTc) greater than $440 \mathrm{~ms}$ on the electrocardiogram (EKG)

Patients were evaluated with several neurodevelopment and behaviour scales, and quality of life and sleep scales were used for their families and caregivers.

\subsection{Dose Titration}

Low doses of SRI were chosen to start with, in order to 
avoid potential undesirable effects. The trial with the two drugs lasted three months. Slow increase titration is summarised in Table 2.

In case of lower therapeutic effect than expected, introduction a new-generation neuroleptic drug (risperidone or aripripazol) at low doses was considered.

\subsection{Evaluation Scales}

In order to provide information to assess the baseline behavior of patients, they were evaluated with the Mullen scale for neurodevelopment, the Aberrant Behavior Checklist (ABC scale, completed by parents and teachers), and quality of sleep and quality of life scales before starting the trial. These were preformed again after treatment.

Once the treatment was started, telephone contact was established weekly for five weeks and then every month for three months. Parents or caregivers had a contact e-mail address for enquiries. Adverse events were registered, and if any serious adverse effect was observed, the patient was withdrawn from treatment while continuing in the study.

\subsection{Data Collection}

- The following tests were performed in all patients before inclusion in the study:

a) Video EEG

b) $\mathrm{EKG}$

c) Blood cell count (BCC), liver function including bilirubin and enzymes, basic biochemistry analysis, including calcium, phosphorus, alkaline phosphatase, 25-dihydroxycholecalciferol, and IGF-1

d) Fasting salivary cortisol (obtained during the first hour after awakening in the morning)

- Data collection pre-treatment included:

1) Questionnaire for parents documenting patient clinical history and noting of any problems or concerns. 2) Specific record of the absence or existence of family history of mental disorders.

3) Behavioural assessment by $\mathrm{ABC}$ at school during the last month prior to the study.

4) Sleep problems referred by the parents through a quality of sleep questionnaire one month prior to the study.

Table 2. Treatment titration.

\begin{tabular}{cccccc}
\hline & $1^{\text {st }}$ week & $2^{\text {nd }}$ week & $3^{\text {rd }}$ week & $4^{\text {th }}$ week & $5^{\text {th }}$ week \\
\hline $\begin{array}{c}\text { Venlafaxine } \\
50 \mathrm{mg}\end{array}$ & $12.5 \mathrm{mg}$ & $25 \mathrm{mg}$ & $50 \mathrm{mg}$ & $50 \mathrm{mg}$ & $50 \mathrm{mg}$ \\
$\begin{array}{c}\text { Citalopram } \\
20 \mathrm{mg}\end{array}$ & $5 \mathrm{mg}$ & $10 \mathrm{mg}$ & $15 \mathrm{mg}$ & $20 \mathrm{mg}$ & $20 \mathrm{mg}$ \\
\hline
\end{tabular}

5) Quality of life questionnaire completed by parents prior to the study.

Post-treatment measures:

1) $\mathrm{ABC}$ post-treatment questionnaire, quality of life questionnaire, and Mullen and Vineland scales were obtained 3 months after treatment onset. These values were compared with the ones pre-treatment for each Patient using the Pearson product-moment correlation.

2) EEG, EKG, BCC, liver function, including calcium, phosphorus, alkaline phosphatase, 25-dihydroxycholecalciferol, and IGF-18. Salivary cortisol was measured again 3 months after study onset.

\subsection{Cortisol Levels in Saliva}

Saliva samples were obtained by a cotton ball wetted in the patient's mouth at 8 am upon awakening, after 8 hours fasting. To minimize bias due to multiple technicians and to reduce cost and time, all samples were processed at the same time, with the same machine as previously described elsewhere [31]. Samples were kept in the refrigerator until testing.

Although cortisol levels in saliva have already been correlated with blood cortisol levels [31,32], samples from 2 healthy children and one healthy young adult were also obtained (data not shown).

\section{Results}

Although this study was proposed to 15 patients, only 11 families agreed to participate. All 15 children met inclusion criteria and none of them presented any of the exclusion criteria. The main reason for declining participation was dealing with antidepressant drugs. Also, families would rather cope with mood tantrums or occasional brief sad mood periods than add a new drug to their children's lives.

No serious adverse reactions such as seizures or serotonin syndrome were observed.

Three of the 11 patients did not complete the neuropsychological evaluation due to traveling issues (they lived far from the center, with difficult transport options). The other eight patients completed the tests in the established periods, although increasing dosage was only completed by four of them. Among these, only two (one patient with venlafaxine and another with citalopram) completed the 3 month trail, albeit with mild side effects.

Differences before and after treatment in $\mathrm{ABC}$, quality of sleep and life questionnaires, and Mullen and Vineland score results were not statistically significant. Table 2 shows the statistical correlation (between Vineland scale scores before and after intervention).

Video EEG and EKG before and after treatment remained stable, and so did the rest of the biochemical pa- 
rameters in blood. Blood cell count, liver function, ionogram, calcium, phosphorus, alkaline phosphatase, 25-dihydroxycholecalciferol and IGF-1 remained within normal limits both before and after treatment, without significant changes. Table $\mathbf{3}$ summarizes Cortisol laboratory workup.

\subsection{Effects of Venlafaxine}

Five of the eight patients who completed the study received venlafaxine. They were younger than 12 years old, with a predominantly anxious mood.

No major behavior changes were observed, but one patient presented a strange and inappropriate look, as if she was experiencing some frightening vision, after the first dose of venlafaxine. This facial expression disappeared a few hours afterwaragain. The patient completed the study without pharmacological treatment. Three more patients showed a "decrease inenergy" in their everyday activities, as expected, so venlafaxine was also discontinued.

\subsection{Effects of Citalopram}

Only one of the eight patients who completed the study (aged 26 years old, with predominance of depression mood) received citalopram. She initially presented a slight worsening of appetite, but then showed, progressively, a slight improvement of her self-aggression movements.

\subsection{New Generation Neuroleptics}

Two of the eight patients who completed the study were on risperidone at the moment of the study onset, and this treatment was not modified; only one patient needed to slightly increase the dose due to increased anxiety, with a good clinical response.

\subsection{Cortisol Levels in Saliva}

At least four patients showed a decrease in saliva cortisol levels one month after treatment, although this was not statistically significant (Table 4 and Figure 1).
Basal cortisol levels for patients 3 and 8 could not be tested because of insufficient saliva sample. This information was only obtained at the end of the study due to the laboratory technique, as explained in 2.5.

Except for patient 4, who only received one dose of venlafaxine, and patient 1 , who did not modify her treatment with risperidone, the rest of the tested patients (4 patients) presented a decrease in cortisol levels in saliva one month after treatment onset.

\section{Discussion}

Mood and behavioural problems are among the most anguishing issues for families of children with cognitive disabilities. They are hard to manage, and response to pharmacological treatment is not always as good as expected. Sometimes, a drug may work for a while and later on become less effective. If a biological marker could help measure anxiety or mood troubles, it would be easier to evaluate the effect of the different neuropsychiatric drugs on patients. This is especially appropriate in the case of Rett children, who also present limitations in verbal language.

Although none of the 15 selected patients presented exclusion criteria for this study, when told what type of drug was going to be tested, some parents rejected their participation. Also, the fact that it was a pilot study for these SSRI and NSRI drugs (albeit previously used to treat children), was another for declining the invitation.

Low doses of SRI were chosen to start with, in order to avoid potential undesirable effects, but as caregivers did not see a significant improvement, or even a "loss of energy" attitude, some withdrew administration. It is possible that if titration had been faster, positive effects would have been shown.

The alteration of facial expression referred by the family of patient 4 could be interpreted as a greater sensitivity of some Rett patients to some psychoactive drugs, as observed for methylphenidate. This patient is now on risperidone, with improvement in her behaviour.

Table 3. Statistical correlation (Pearson product-moment correlation) between Vineland scale scores before and after intervention through.

\begin{tabular}{|c|c|c|c|c|c|}
\hline & Expressive language & Receptive language & Visual reception & Fine motor skills & Gross motor skills \\
\hline Expressive language & 0.566 & $0.864^{\mathrm{a}}$ & $0.643^{\mathrm{b}}$ & $0.709^{b}$ & $0.771^{\mathrm{a}}$ \\
\hline Receptive language & 0.624 & 0.609 & 0.473 & 0.321 & 0.566 \\
\hline Daily skills & 0.373 & $0.777^{\mathrm{a}}$ & 0.551 & $0.738^{\mathrm{b}}$ & 0.621 \\
\hline Interpersonal relationships & 0.629 & $0.835^{\mathrm{a}}$ & 0.620 & 0.575 & $0.782^{\mathrm{a}}$ \\
\hline Fine motor skills & 0.392 & $0.839^{\mathrm{a}}$ & $0.779^{\mathrm{a}}$ & $0.867^{\mathrm{a}}$ & $0.790^{\mathrm{a}}$ \\
\hline Gross motor skills & 0.490 & $0.731^{\mathrm{b}}$ & $0.806^{\mathrm{a}}$ & $0.888^{\mathrm{a}}$ & $0.871^{\mathrm{a}}$ \\
\hline
\end{tabular}

${ }^{\mathrm{a} C}$ Correlation is significant at 0.01 level (bilateral); ${ }^{\mathrm{b}}$ Correlation is significant at 0.05 level (bilateral). 
Table 4. Electrophysiology and laboratory workup before and after treatment. Cortisol levels are marked in grey.

\begin{tabular}{|c|c|c|c|c|c|c|c|c|c|c|}
\hline \multirow{3}{*}{$\begin{array}{c}\text { Patient } \\
1\end{array}$} & \multirow{3}{*}{$\begin{array}{c}\begin{array}{c}\text { Family mood } \\
\text { disorder }\end{array} \\
\begin{array}{c}\text { Maternal } \\
\text { grandmother } \\
\text { depression }\end{array}\end{array}$} & \multirow{3}{*}{$\begin{array}{c}\text { Current treatment } \\
\begin{array}{c}\text { Risperidone, valproate, } \\
\text { carnitine }\end{array}\end{array}$} & \multirow{3}{*}{$\begin{array}{c}\text { Epilepsy } \\
\begin{array}{c}\text { Yes, } \\
\text { controled }\end{array}\end{array}$} & \multirow{3}{*}{$\begin{array}{c}\text { Treatment } \\
\text { intervention } \\
\begin{array}{c}\text { Risperidone, } \\
\text { unmodified }\end{array}\end{array}$} & \multicolumn{6}{|c|}{ Saliva cortisol $\mu \mathrm{g} / \mathrm{L}$ (NV 0.9-15.5) } \\
\hline & & & & & \multirow{2}{*}{$\begin{array}{c}\text { Pretreatment } \\
\\
0.89\end{array}$} & \multicolumn{3}{|c|}{$\begin{array}{l}5^{\text {th }}-6^{\text {th }}-8^{\text {th }} \text { week } \\
\text { posttreatment }\end{array}$} & \multicolumn{2}{|c|}{$\begin{array}{c}3-4 \text { months } \\
\text { posttreatment }\end{array}$} \\
\hline & & & & & & \multicolumn{3}{|c|}{3.42} & \multicolumn{2}{|c|}{1.37} \\
\hline 2 & no & $\begin{array}{l}\text { Risperidone, levetirazetam, } \\
\text { melatonine }\end{array}$ & $\begin{array}{l}\text { Yes, } \\
\text { controled }\end{array}$ & $\begin{array}{l}\text { Risperidone, } \\
\text { dose increase }\end{array}$ & 7.53 & \multicolumn{3}{|c|}{2.58} & \multicolumn{2}{|c|}{2.41} \\
\hline 3 & no & $\begin{array}{l}\text { Clobazam, trihexiphenidil, } \\
\text { valproate }\end{array}$ & $\begin{array}{l}\text { Yes, } \\
\text { controled }\end{array}$ & Venlafaxine & $\begin{array}{l}\text { Not enough } \\
\text { sample }\end{array}$ & \multicolumn{3}{|c|}{6.06} & \multicolumn{2}{|c|}{2.88} \\
\hline 4 & $\begin{array}{l}\text { Maternal } \\
\text { grandmother } \\
\text { depression }\end{array}$ & Valproate & $\begin{array}{l}\text { Yes, } \\
\text { controled }\end{array}$ & Venlafaxine & 1.48 & \multicolumn{3}{|c|}{2.42} & \multicolumn{2}{|c|}{2.8} \\
\hline 5 & $\begin{array}{l}\text { Mother reactive } \\
\text { depression }\end{array}$ & $\begin{array}{l}\text { Carbamazepine, vigabatrin, } \\
\text { omeprazol, motilium }\end{array}$ & $\begin{array}{l}\text { Yes, } \\
\text { controled }\end{array}$ & Venlafaxine & 6.0 & \multicolumn{3}{|c|}{$0.44(\downarrow)$} & \multicolumn{2}{|c|}{4.10} \\
\hline 6 & no & Valproate, etosuximide & $\begin{array}{l}\text { Yes, } \\
\text { controled }\end{array}$ & Venlafaxine & 3.0 & 1.2 & 1.56 & 2.64 & 1.65 & 3.82 \\
\hline 7 & $\begin{array}{l}\text { Maternal } \\
\text { grandmother } \\
\text { depression }\end{array}$ & $\begin{array}{l}\text { Ferrum, fiber, omeprazol, } \\
\text { valproate, levetiracetam }\end{array}$ & $\begin{array}{l}\text { Yes, } \\
\text { controled }\end{array}$ & Venlafaxine & 1.07 & & 0.67 & & 2.0 & 1.14 \\
\hline 8 & no & $\begin{array}{l}\text { Carbamazepine, clonazepam, } \\
\text { levomepromazine, omeprazol, folaxin }\end{array}$ & $\begin{array}{l}\text { Yes, } \\
\text { controled }\end{array}$ & Citalopram & $\begin{array}{l}\text { Not enough } \\
\text { sample }\end{array}$ & & 3.24 & & 3.36 & 3.48 \\
\hline
\end{tabular}

$\mu \mathrm{g} / \mathrm{L}$

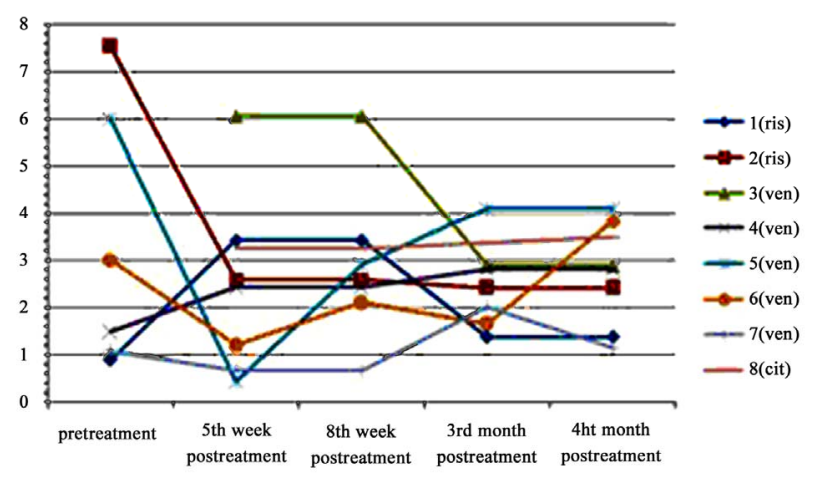

Ris: Risperidone; Ven: venlafaxine; Cit: citalopram.

Figure 1. Cortisol levels in saliva during the study period.

\subsection{Evaluation Scales}

One of the main issues in this study was how to measure behavior. Many of the behavioural problems related to Rett syndrome and in general to children with severe cognitive disabilities interfere with the evaluation of their mental abilities. Attention difficulties, hyperactivity, sensorial deficiencies, and poor performance due to social disturbances or limited understanding of the task may lead to underscoring of their skills, especially when testing in an unfamiliar context [33]. It is also important to consider that many of the tests which are used to measure cognitive abilities show a marked "ground effect" when direct scores are converted to standardized scores based on data for normative samples, which makes it even more difficult to obtain an estimation of the real abilities of these children. Also, while most cognitive tests do not measure cognitive functions under four standard deviations below the mean scores, adaptative behaviour tests such as Vineland Adaptative Behavior Scale are powerful enough to measure up to five standard deviations below the media. This fact makes it difficult to establish realistic correlations between cognitive functions and daily functional behaviour with these children [34]. However, regarding this small group of children, among functional tests, Vineland scale seems to be more accurate than Mullen scale to evaluate global functions in these patients.

Among other aims, the authors tried to identify the most suitable behaviour test to identify and measure mood disorders in RTT, and then use it as a semi-quantitative tool to evaluate clinical improvement after intervention. Both the Mullen and Vineland scales failed to show differences before and after treatment. This could be due to a lack of efficacy of the drugs at the chosen doses, but it is more likely that the tests are not sensitive enough to 
evaluate subtle changes in mood and behaviour. Indeed, mood and behavior depend on so many environmental factors that it remains extremely difficult to isolate them from the context.

\subsection{Quality of Life and Quality of Sleep Questionnaires}

Quality of life and sleep questionnaires were completed in order to evaluate possible changes in everyday life after treatment onset. However, quality of life answers depend also on the caregiver's mood and attitude towards the child's difficulties. In this small group of patients, the quality of life and sleep questionnaires failed to identify concrete mood problems: listening to the caregivers was found to be more effective to listen to which difficulties the parents identified than to devote time to completing the questionnaires.

In contrast to the positive effects of desimipramine (a SNRI) on rats with Mecp2 mutations and RTT symptoms previously reported [35], our patients' quality of life and sleep did not experiment significant changes.

\subsection{Cortisol Levels in Saliva}

Cortisol levels in saliva seemed an apt biochemical marker of stress in these children, as this allowed avoiding venous punctures in children with cognitive disability. However, some small difficulties were observed: to prevent children from swallowing the cotton ball, a thread was inserted to hold it while the child chewed it. Sometimes children would chew it properly, but others would keep it almost dry. Given that all samples were analyzed at the same time, it was not possible to obtain a proper baseline sample of the two patients who initially did not produce enough saliva.

Although not statistically significant, there was a tendency of cortisol to show a decrease in venlafaxine greater than that of risperidone.

No correlation could be established between age and the effects of the two drugs, although the oldest patient, who presented a more depressive phenotype, is the one who presented a slight clinical improvement (not statistically significant); no correlation could be established with the genotype, given the small size of the sample and the absence of significant differences before and after treatment.

To conclude, serotonin reuptake might be impaired in RTT, as experimental studies have demonstrated, but the clinical effects of venlafaxine (SNRI) and citalopram (SSRI) in RTT patients were not clinically relevant in this small group.

An important limitation of this study was the small size of the sample. Future studies should involve larger samples and longer trials in order to increase reliability and generalization of the findings and yield more realistic results.

\section{Acknowledgements}

This small study was made possible thanks to a BIORETT research grant, and to the confidence and commitment of the families of RTT girls, who invested their time and energy to trying to improve the quality of life of their children and others. The authors also thank the Associations of Rett Syndrome in Spain.

\section{REFERENCES}

[1] B. Hagberg, "Clinical Manifestations and Stages of Rett Syndrome," Mental Retardation and Development Disability Research Review, Vol. 8, No. 2, 2002, pp. 61-65. doi: $10.1002 / \mathrm{mrdd} .10020$

[2] E. Trevathan and S. Naidu, "The Clinical Recognition and Differential Diagnosis of Rett Syndrome," Journal of Child Neurology, Vol. 3, No. S6, 1988, p. 16.

[3] P. Moretti, J. M. Levenson, F. Battaglia, R. Atkinson, R. Teague, et al., "Learning and Memory and Synaptic Plasticity Are Impaired in a Mouse Model of Rett Syndrome," Journal of Neurosciences, Vol. 1, No. 26, 2006, pp. 319-327.

[4] M. E. Blue, S. Naidu and M. V. Johnston, "Development of Amino Acid Receptors in Frontal Cortex from Girls with Rett Syndrome," Annals of Neurology, Vol. 45, No. 4, 1999, pp. 541-545. doi:10.1002/1531-8249(199904)45:4<541::AID-ANA21> 3.0.CO;2-2

[5] R. Lappalainen and R. S. Riikonen, "High Levels of CSF Glutamate in Rett Syndrome," Pediatric Neurology, Vol. 15, No. 3, 1996, pp. 213-216. doi:10.1016/S0887-8994(96)00218-4

[6] A. Horská, L. Farage, G. Bibat, L. M. Nagae, W. E. Kaufmann, P. B. Barker, et al., "Brain Metabolism in Rett Syndrome: Age, Clinical, and Genotype Correlations," Annals of Neurology, Vol. 65, No. 1, 2009, pp. 90-97. doi:10.1002/ana.21562

[7] H. T. Chao, H. Y. Zoghbi and C. Rosenmund, "MeCP2 Controls Excitatory Synaptic Strength by Regulating Glutamatergic Synapse Number," Neuron, Vol. 56, No. 1, 2007, pp. 58-65. doi:10.1016/j.neuron.2007.08.018

[8] L. Medrihan, E. Tantalaki, G. Aramuni, V. Sargsyan, I. Dudanova, M. Missler, et al., "Early Defects of GABAergic Synapses in the Brain Stem of a MeCP2 Mouse Model of Rett Syndrome," Journal of Neurophysiology, No. 99, pp. 112-121.

[9] J. C. Viemari, "Noradrenergic Modulation of the Respiratory Neural Network," Respiratory Physiology and Neurobiology, Vol. 1-2, No. 164, 2008, pp. 123-130.

[10] D. S. Paterson, E. G. Thompson, R. A. Belliveau, B. A. Antalffy, F. L. Trachtenberg, D. D. Armstrong, et al., "Serotonin Transporter Abnormality in the Dorsal Motor $\mathrm{Nu}$ cleus of the Vagus in Rett Syndrome, Potential Implications for Clinical Autonomic Dysfunction," Journal of Neuropathology and Experimental Neurology, Vol. 11, 
No. 64, 2005, pp. 1018-1027. doi:10.1097/01.jnen.0000187054.59018.f2

[11] C. Chiron, C. Bulteau, C. Loc'h, C. Raynaud, B. Garreau, A. Syrota, et al., "Dopaminergic D2 Receptor SPECT Imaging in Rett Syndrome: Increase of Specific Binding in Striatum," Journal of Nuclear Medecine, Vol. 10, No. 34, 1993, pp. 1717-1721.

[12] S. Ide, M. Itoh and Y. Goto, "Defect in Normal Developmental Increase of the Brain Biogenic Amine Concentrations in the Mecp2-Null Mouse," Neurosciences Letters, Vol. 386, No. 1, 2005, pp. 14-17. doi:10.1016/j.neulet.2005.05.056

[13] E. Shirazi and J. Alaghband-Rad, "An Open Trial of Citalopram in Children and Adolescents with Depression," Journal of Child and Adolescent Psychopharmacology, Vol. 15, No. 2, 2005, pp. 233-239. doi:10.1089/cap.2005.15.233

[14] K. D. Wagner, A. S. Robb, R. L. Findling, J. Jin, M. M. Gutierrez and W. E. Heydorn, "A Randomized, PlaceboControlled Trial of Citalopram for the Treatment of Major Depression in Children and Adolescents," American Journal of Psychiatry, Vol. 161, No. 6, 2004, pp. 1079-1083. doi:10.1176/appi.ajp.161.6.1079

[15] L. B. Namerow, P. Thomas, J. Q. Bostic, J. Prince and M. C. Monuteaux, "Use of Citalopram in Pervasive Developmental Disorders," Journal of Developmental and Behavioral Pediatrics, Vol. 24, No. 2, 2003, pp. 104-108. doi:10.1097/00004703-200304000-00005

[16] J. L. Couturier and R. Nicolson, "A Retrospective Assessment of Citalopram in Children and Adolescents with Pervasive Developmental Disorders," Journal of Child and Adolescent Psychopharmacology, Vol. 12, No. 3, 2002, pp. 243-248. doi:10.1089/104454602760386932

[17] J. L. Baumgartner, G. L. Emslie and M. L. Crismon, "Citalopram in Children and Adolescents with Depression or Anxiety," Annals of Pharmacotherapy, Vol. 36, No. 11, 2002, pp. 1692-1697. doi:10.1345/aph.1C078

[18] J. L. Armenteros and J. E. Lewis, "Citalopram Treatment for Impulsive Aggression in Children and Adolescents: An Open Pilot Study," Journal of the American Academy of Child \& Adolescent Psychiatry, Vol. 41, No. 5, 2002, pp. 522-529. doi:10.1097/00004583-200205000-00009

[19] G. J. Emslie, R. L. Findling, P. P. Yeung, N. R. Kunz and Y. Li, "A Randomized Controlled Trial of Venlafaxine ER versus Placebo in Pediatric Social Anxiety Disorder," Biological Psychiatry, Vol. 62, No. 10, 2007, pp. 11491154. doi:10.1016/j.biopsych.2007.02.025

[20] G. J. Emslie, R. L. Findling, P. P. Yeung, N. R. Kunz and Y. Li, "Venlafaxine ER for the Treatment of Pediatric Subjects with Depression: Results of Two Placebo-Controlled Trials," Journal of the American Academy of Child Adolescent Psychiatry, Vol. 4, No. 46, pp. 479-488.

[21] G. J. Emslie, P. P. Yeung and N. R. Kunz, "Long-Term, Open-Label Venlafaxine Extended-Release Treatment in Children and Adolescents with Major Depressive Disorder. CNS Spectrums, Vol. 3, No. 12, 2007, pp. 223-233.

[22] M. A. Rynn, M. A. Riddle, P. P. Yeung and N. R. Kunz, "Efficacy and Safety of Extended-Release Venlafaxine in the Treatment of Generalized Anxiety Disorder in Children and Adolescents: Two Placebo-Controlled Trials," American Journal of Psychiatry, Vol. 164, No. 2, 2007, pp. 290-300. doi:10.1176/appi.ajp.164.2.290

[23] E. B. Weller, R. A. Weller and G. P. Davis, "Use of Venlafaxine in Children and Adolescents: A Review of Current Literature," Depression and Anxiety, Vol. 12, No. S1, 2000, pp. 85-89.

doi:10.1002/1520-6394(2000)12:1+<85::AID-DA12>3.0. CO;2-0

[24] B. E. McGill, S. F. Bundle, M. B. Yaylaoglu, J. P. Carson, C. Thaller and H. Y. Zoghbi, "Enhanced Anxiety and StressInduced Corticosterone Release Are Associated with Increased CRH Expression in Mouse Model of Rett Syndrome," Proceedings of the National Academy of Sciences of the USA, Vol. 103, No. 48, 2006, pp. 1826718272. doi: $10.1073 /$ pnas. 0608702103

[25] K. Greaves-Lord, R. F. Ferdinand, A. J. Oldehinkel, F. E. Sondeijker, J. Ormel and F. C. Verhulst, "Higher Cortisol Awakening Response in Young Adolescents with Persistent Anxiety Problem," Acta Psychiatrica Scandinavica, Vol. 116, No. 2, 2007, pp 137-144. doi:10.1111/j.1600-0447.2007.01001.x

[26] L. M. Jansen, C. C. Gispen-de Wied, M. A. Jansen, R. J. van der Gaag, W. Matthys and H. van Engeland, "Pituitary-Adrenal Reactivity in a Child Psychiatric Population: Salivary Cortisol Response to Stressors," European Neuropsychopharmacology, Vol. 1-2, No. 9, 1999, pp. 67-75.

[27] D. Van West, S. Claes, J. Sulon and D. Deboutte, "Hypothalamic-Pituitary-Adrenal Reactivity in Prepubertal Children with Social Phobia," Journal of Affective Disorders, Vol. 111, No. 2, 2008, pp. 281-290.

doi:10.1016/j.jad.2008.03.006

[28] B. A. Corbett, S. Mendoza, M. Abdullah, J. A. Wegelin and S. Levine, "Cortisol Circadian Rhythms and Response to Stress in Children with Autism," Psychoneuroendocrinology, Vol. 31, No. 1, 2006, pp. 59-68. doi:10.1016/j.psyneuen.2005.05.011

[29] J. G. Rosmalen, A. J. Oldehinkel, J. Ormel, A. F. de Winter, J. K. Buitelaar and F. C. Verhulst, "Determinants of Salivary Cortisol Levels in 10-12 Year Old Children; A Population-Based Study of Individual Differences," Psychoneuroendocrinology, Vol. 30, No. 5, 2005, pp. 483495. doi:10.1016/j.psyneuen.2004.12.007

[30] D. S. Jessop and J. M. Turner-Cobb, "Measurement and Meaning of Salivary Cortisol: A Focus on Health and Disease in Children," Stress, Vol. 11, No. 1, 2008, pp. 1-14. doi:10.1080/10253890701365527

[31] M. Neu, M. Goldstein, D. Gao and M. L. Laudenslager, "Salivary Cortisol in Preterm Infants: Validation of a Simple Method for Collecting Saliva for Cortisol Determination," Early Human Development, Vol. 1, No. 83, 2007, pp. 4754.

[32] K. Hanrahan, A. M. McCarthy, C. Kleiber, S. Lutgendorf and E. Tsalikian, "Strategies for Salivary Cortisol Collection and Analysis in Research with Children. Applied Nursing Research, Vol. 19, No. 2, 2006, pp. 95-101. doi:10.1016/j.apnr.2006.02.001

[33] N. Akshoomoff, "Use of the Mullen Scales of Early Learn- 
ing for the Assessment of Young Children with Autism Spectrum Disorders," Child Neuropsychoog, Vol. 12, No. 4-5, 2006, pp. 269-277. doi:10.1080/09297040500473714

[34] D. Hessl, D. V. Nguyen, C. Green, A. Chavez, F. Tassone, R. J. Hagerman, et al., "A Solution to Limitations of Cognitive Testing in Children with Intellectual Disabilities: The Case of Fragile X Syndrome," Journal of Neurodevelop- ment Disorders, Vol. 1, No. 1, 2009, pp. 33-45. doi:10.1007/s11689-008-9001-8

[35] C. H. Pan and S. Tsai, "Early Intervention with Psychostimulants or Antidepressants to Increase Methyl-CpG-Binding Protein 2 (MeCP2) Expressions: A Potential Therapy for Rett Syndrome," Medical Sciences Monitor, Vol. 18, No. 1, 2012, pp. 1-3. doi:10.12659/MSM.882183 